\title{
Patterns of global DNA and histone methylation appear to be similar in normal, dysplastic and neoplastic oral epithelium of humans
}

\author{
Chandrika J. Piyathilake ${ }^{\mathrm{a}, *}$, Walter C. Bell ${ }^{\mathrm{b}}$, Jennifer Jones ${ }^{\mathrm{b}}$, Olga L. Henao ${ }^{\mathrm{c}}$, Douglas C. Heimburger ${ }^{\mathrm{a}}$, \\ Alain Niveleau ${ }^{\mathrm{d}}$ and William E. Grizzle ${ }^{\mathrm{b}}$

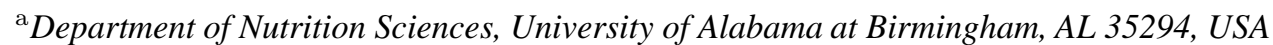 \\ ${ }^{\mathrm{b}}$ Department of Pathology, University of Alabama at Birmingham, AL 35294, USA \\ ${ }^{\mathrm{c}}$ Department of Epidemiology, University of Alabama at Birmingham, AL 35294, USA \\ ${ }^{\mathrm{d}}$ Laboratory of Virology, Faculty of Medicine, University Joseph Fourier of Grenoble, Avenue Gresivaudan, 38706 \\ La Tronche, France
}

\begin{abstract}
Although there is growing interest in the possibility that alterations in histone methylation may play a role in carcinogenesis, it has not been explored adequately in humans. Similarly, there are no reports of associations between this and a similar epigenetic event, DNA methylation. Using immunohistochemical staining, we compared the methylation of DNA and histones in histopathologically normal oral epithelium, dysplastic oral lesions, and squamous cell cancers (SCCs) from subjects with squamous cell cancer $(n=48)$ with those of normal oral epithelium from subjects without oral cancer $(n=93)$ who were matched on age and race. Monoclonal antibodies specific for 5 methyl cytosine (5-mc), lysine 4 of histone $\mathrm{H}_{3}\left(\mathrm{H}_{3}-\mathrm{Lys}_{4}\right)$, and lysine 9 of histone $\mathrm{H}_{3}\left(\mathrm{H}_{3}\right.$-Lys9) were used in this study. The percentages of cells positive and a weighted average of the immunostaining intensity scores were calculated for each of these tissues, and Spearman correlation analyses were employed to study associations between DNA and histone methylation. Correlations between DNA and histone methylation, $\mathrm{H}_{3}-\mathrm{Lys}_{4}$ and $\mathrm{H}_{3}$ - Lys9 were positive and statistically significant in all tissue types; they were strongest in normal oral epithelium from non-cancer subjects ( $r=0.63, p<0.001$ and $r=0.62, p<0.001$ respectively). Similarly, the positive correlations between $\mathrm{H}_{3}$ - Lys 4 and $\mathrm{H}_{3}$ - Lys9 were statistically significant in all tissue types and strongest in normal oral epithelium from non-cancer subjects $(r=0.77, p<0.001)$. Patterns of DNA and histone methylation are similar in tissues across the spectrum of oral carcinogenesis, and there is a significant positive association between these two epigenetic mechanisms.
\end{abstract}

\section{Introduction}

The major mechanisms in the epigenetic regulation of genes involve changes in global/CpG island/gene-

${ }^{*}$ Corresponding author: Chandrika J. Piyathilake, Department of Nutrition Sciences, Division of Nutritional Biochemistry and Molecular Biology, University of Alabama at Birmingham (UAB), 1675 University Blvd, Webb 318A, Birmingham, AL 35294-3360, USA. Tel.: +1 205975 5398; Fax: +1 205996 2859; E-mail: piyathic@ uab.edu. specific methylation of DNA and modifications in histones. Global DNA hypomethylation has been implicated in chromosome instability, loss of imprinting, abnormal chromosomal structures and activation of oncogenes and reactivation of transposons of retroviruses, all of which may contribute to carcinogenesis $[1,10$, 13,15]. Ample evidence also exists to support the notion that DNA hypermethylation events in $\mathrm{CpG}$ islands can act as a primary inactivating event contributing directly to tumorigenesis $[9,14]$. Methylation of specific lysine residues in histone tails has been proposed to 
function as a stable epigenetic marker that directs biological functions ranging from transcriptional regulation to heterochromatin assembly [8]. Methylation of a specific lysine residue (at positions 4 and 9 in the amino acid chain) in histone $\mathrm{H}_{3}$ has been shown to be involved in the regulation of chromatin structure [16].

There is growing evidence that interplay exists between DNA methylation and histone modifications. It has been reported that histone modification is crucial to the process of DNA methylation in some organisms such as Neurospora where abrogation of $\mathrm{H}_{3}$-Lys9 methylation results in loss of DNA methylation [6]. However, for hypermethylated tumor suppressor genes in human cancer, DNA hypermethylation appears to be dominant over histone deacytylation part of the histone code for maintaining a silenced state and DNA demethylating agent 5-Aza-dC, but not the histone deacetylase inhibitor TSA, reactivates the expression of these genes [5].

Subsequent studies have shown that DNA hypermethylation, either directly or indirectly, through suppressing transcription, specifies for repressive histone modification at tumor suppressor gene promotion sites [7]. Loss of $\mathrm{CpG}$ methylation is also shown to be correlated strongly with loss of $\mathrm{H}_{3}$-Lys9 methylation in patients with Beckwith-Wiedemann Syndrome [11]. Despite this growing interest in these epigenetic mechanisms, to our knowledge, associations between global changes in DNA and histone methylation have not been reported in humans. We evaluated these associations in malignant, pre-malignant, uninvolved, and normal tissues of the oral cavity.

\section{Materials and methods}

Subjects and Tissue Specimens. From a list of patients diagnosed with oral lesions between 1984 and 2000 at the Veterans Administration Medical Center in Birmingham, AL, we identified 57 subjects with squamous cell cancers (SCCs) and 115 subjects with normal oral epithelium (non-cancer subjects). Among the SCC subjects, 44 had adequate tissue specimens for evaluation (formalin fixed and paraffin embedded blocks), and among these, we found malignant tissues adequate for evaluation in 39 subjects. 44 and 42 of the cancer specimens had histopathologically normal appearing uninvolved oral epithelium and dysplastic lesions, respectively. All of the non-cancer subjects had adequate normal oral epithelium to be evaluated. All 39 subjects with adequate SCC tissues were included in the study. The control group consisted of 93 noncancer subjects matched on age and race (two for each cancer case except for 3 cases, for whom only one noncancer case could be matched). One tissue block from each non-cancer subject was selected to provide a tissue section that contained adequate normal and uninflamed oral epithelium. One or more tissue blocks from each subject with SCC were selected to provide sections that contained samples of uninvolved oral epithelium and dysplasia, in addition to the invasive carcinomas.

\section{Histological criteria and classification of lesions}

Oral epithelium was classified histologically as normal (in non-cancer specimens), uninvolved (SCCassociated, but histopathologically normal appearing), or dysplastic by one of the pathologists (WCB) involved in the study.

\section{Immunohistochemical analysis}

Our methods of immunohistochemical analysis with various antibodies (with/without various antigen retrieval techniques) have been reported previously [2, 17]. A comparison of results with and without different antigen retrieval techniques revealed that the following protocols gave the optimal results: the slides containing $4 \mu$ thick paraffin tissue sections were deparaffinized in xylene, placed in $0.01 \mathrm{M}$ citric acid, $\mathrm{pH}$ 6.0, and boiled in a microwave set at full power for 10 minutes. After antigen retrieval, the sections except for histone assays were cooled, rinsed in $\mathrm{dH}_{2} \mathrm{O}$, and placed in $3.5 \mathrm{~N} \mathrm{HCl}$ for 15 minutes at room temperature to open the DNA. The sections were rinsed with $\mathrm{dH}_{2} \mathrm{O}$ and treated with $3.0 \% \mathrm{H}_{2} \mathrm{O}_{2}$ for 5 minutes to quench endogenous peroxidase activity. Sections were incubated with preimmune goat serum (1\%) for 1 hour at room temperature to suppress nonspecific staining and then subsequently incubated with each antibody for 1 hour at room temperature. The monoclonal antibody specific for 5-methyl cytosine $(5-\mathrm{mc})$ was provided by one of the investigators (AN) and the methylation patterns observed in other cancers with this antibody are published elsewhere [3,4]. Antibodies used in histone methylation assays (Anti-dimethyl-Histone $\mathrm{H}_{3}$ [Lys4]-Catalog \# 07-030 and Anti-dimethyl-Histone $\mathrm{H}_{3}$ [Lys9)-Catalog \# 07-212 are commercially available through Upstate Biotechnology, Lake Placid, New York. The concentrations of 5-mc, Lys4 and Lys9 an- 
Table 1

Mean (median) percentage of cells positive and weighted average of the immunostaining scores for 5-mc, H3-lys 4 and H3-lys 9 in normal and uninvolved oral epithelium, dysplasia and squamous cell cancer (SCC)

$\begin{array}{lcccc} & \begin{array}{c}\text { Normal oral epithelium } \\ \text { of non-cancer }(n=93)\end{array} & \begin{array}{c}\text { Uninvolved oral epithelium } \\ \text { of cancer }(n=44)\end{array} & \begin{array}{c}\text { Dysplasia of } \\ \text { cancer }(n=42)\end{array} & \begin{array}{c}\text { Cancer } \\ (n=39)\end{array} \\ \text { \% cells positive for 5-mc } & 37(35) & 34(33) & 48(50) & 51(55) \\ \text { Weighted average of 5-mc score } & 0.53(0.47) & 0.48(0.39) & 0.72(0.69) & 0.77(0.80) \\ \% \text { cells positive for H3-lys 4 } & 33(33) & 34(29) & 46(43) & 55(60) \\ \text { Weighted average of H3-lys 4 score } & 0.60(0.56) & 0.52(0.46) & 0.78(0.70) & 0.88(0.90) \\ \text { \% cells positive for H3-lys 9 } & 34(33) & 33(30) & 49(55) & 47(50) \\ \text { Weighted average of H3-lys 9 score } & 0.54(0.42) & 0.48(0.45) & 0.80(0.76) & 0.74(0.70)\end{array}$

tibodies used were 1:2000, 1:50 and $5 \mu \mathrm{g} / \mathrm{ml}$, respectively. Companion matching slides stained with no primary antibody served as controls (deletes). The remainder of the staining procedure was performed using a biotin-streptavidin detection system (Signet, Dedham, MA) as described by the manufacturer. The substrate, diaminobenzidine tetrahydrochloride, was used for visualization of the antigen-antibody complex, and sections were counterstained lightly with hematoxylin. Immunostaining was performed without knowledge of the status (SCC/non-cancer) of the tissues.

\section{Assessment of immunostaining}

Immunostaining for 5-mc was localized in the nuclei of the cells. $\mathrm{H}_{3}$-Lys 4 and $\mathrm{H}_{3}$-Lys9 was mainly localized in the nuclei of the cells, but cytoplasmic staining was seen occasionally in some areas of the epithelium. Only nuclear staining was evaluated for $5-\mathrm{mc}, \mathrm{H}_{3}$-Lys 4 and $\mathrm{H}_{3}$-Lys9. Two observers (CJP and WCB) independently scored the intensity of immunostaining on a scale of 0 (no staining) to $4+$ (intense staining). In addition, the percentages of cells at each intensity were estimated and multiplied by the appropriate intensity score to obtain a weighted average of the immunostaining score. The final score reported is the average of the two observers. A lower score reflects a lower degree of global methylation of DNA or histone.

\section{Statistical analysis}

Descriptive statistics including mean, median, standard deviation (SD) of the mean and range were calculated for the percentage of cells positive for 5-mc, $\mathrm{H}_{3}$-Lys4, and $\mathrm{H}_{3}$-Lys9, and the weighted average of the scores for each type of tissue. Differences in immunostaining between types of tissues were calculated, and either the Wilcoxon Rank Sum or the Wilcoxon Sign Rank test was employed to test for differential staining between different types of tissues. Spearman correlation analyses were employed to test for associations between DNA and histone methylation.

\section{Results}

All subjects in this study were males. The mean age of subjects diagnosed with cancer was $59 \pm 9$ years. The mean age of the non-cancer group was also $59 \pm$ 9 years. $20 \%$ and $80 \%$ of subjects in each group (cancer and non-cancer) were African Americans and Whites respectively. The immunostaining results of different types of tissue are shown in Table 1. There was no significant difference in percentages of cells positive or weighted averages of the immunostaining scores for 5mc, $\mathrm{H}_{3}$-Lys 4 and $\mathrm{H}_{3}$-Lys 9 between uninvolved normal epithelium of cancer subjects and normal epithelium of non-cancer subjects ( $p>0.05$ for all comparisons). The percentages of cells positive and the immunostaining scores for 5-mc, $\mathrm{H}_{3}$-Lys4 and $\mathrm{H}_{3}$-Lys9 were significantly higher in dysplastic lesions and cancer cells compared to normal oral epithelium of non-cancer subjects ( $p<0.05$ for all comparisons). Among cancer subjects, the percentages of cells positive and the immunostaining scores for 5-mc, $\mathrm{H}_{3}$-Lys 4 and $\mathrm{H}_{3}$-Lys9 were significantly higher in dysplastic lesions and in cancer tissues compared to uninvolved oral epithelium ( $p<0.05$ for all comparisons). When matching on age and race was taken into account, the results remained the same suggesting that the differences in the pattern of DNA and histone methylation between cancer and non-cancer are unlikely to be due to differences in age and race. Figure 1 shows the representative patterns of immunohistochemical staining for 5-mc, $\mathrm{H}_{3}$-Lys4, and $\mathrm{H}_{3}$-Lys9 in the normal oral epithelium and in oral cancer. The correlations between 5-mc and $\mathrm{H}_{3}$-Lys4 or $\mathrm{H}_{3}$-Lys9 and between $\mathrm{H}_{3}$-Lys4 and $\mathrm{H}_{3}$-Lys9 using percentages of cells positive for each marker are shown in Table 2. The correlations followed a similar magnitude and statistical significance when weighted score averages were used (data not shown). 

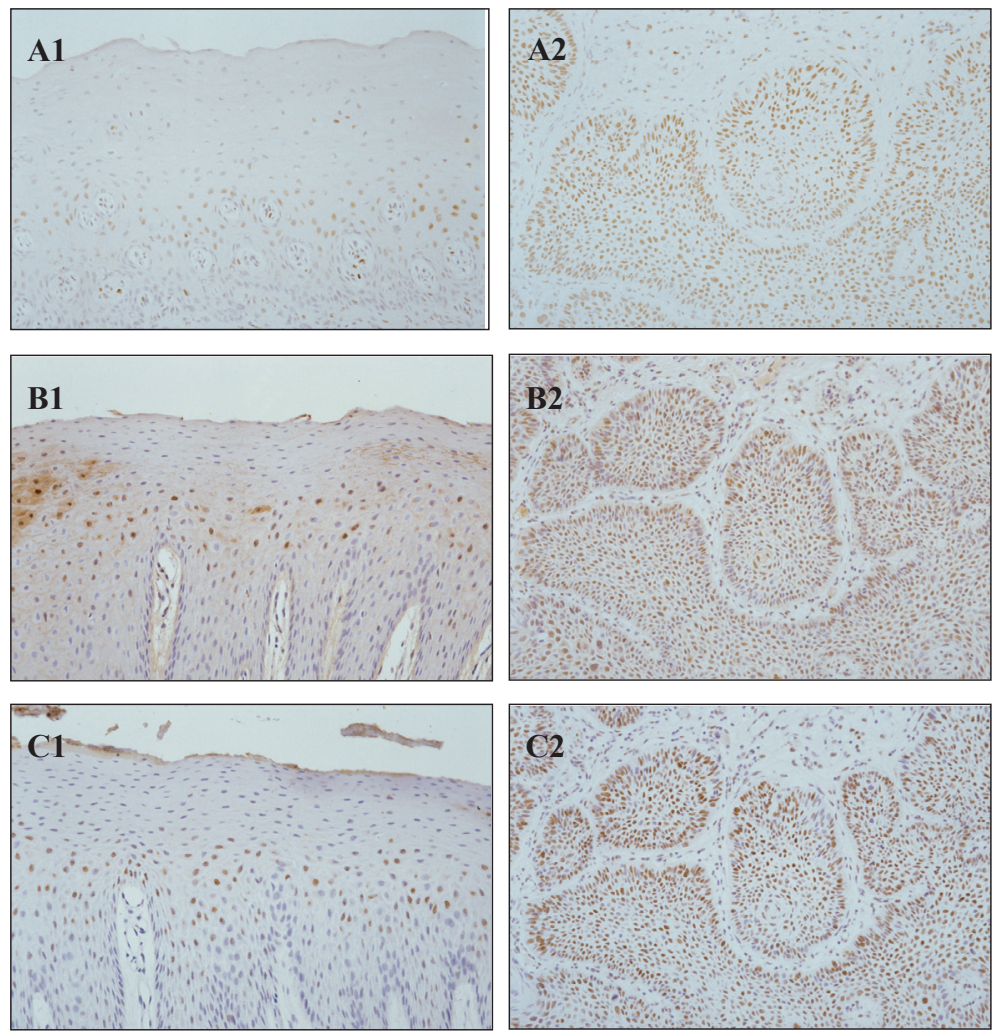

Fig. 1. Imuunohistochemical staining for 5-mc (A1-normal, A2-cancer), H3-Lys4 (B1-normal, B2-cancer) and H3-Lys9 (C1-normal, C2-cancer).

\section{Conclusion}

To our knowledge, there are no reports of the patterns of global histone methylation in specific cells involved in human carcinogenesis. Several studies have reported positive associations between DNA hypermethylation and $\mathrm{H}_{3}$-Lys9 methylation and an inverse association between DNA methylation and $\mathrm{H}_{3}$-Lys4 methylation in specific regions of genes [19]. In this study, we observed that global DNA methylation is positively associated with methylation of both Lys4 and Lys9. Also, we report a significant positive association between methylation of Lys9 and Lys4. Since methyl groups for both DNA and histones are provided by common pathways, it is entirely conceivable that their global methylation status is positively associated. It is also known that the signal for DNA methylation is translated by methyl-CpG binding proteins, such as $\mathrm{MeCP} 2$. $\mathrm{MeCP} 2$ has been reported to induce deacetylation of lysine residues on $\mathrm{H}_{3}$, thus allowing methylation of lysine by histone methyltransferases $[12,18]$.

We previously reported that SCCs of the lung are globally hypomethylated compared to normal bronchial epithelium of non-cancer subjects and SCC associated uninvolved bronchial epithelium, epithelial hyperplasia and dysplasia [3]. Using the same assay methodology, we now report that DNA of dysplastic lesions and SCCs of the oral cavity are significantly hypermethylated compared to uninvolved oral epithelium of the same subjects and to normal oral epithelium of non-cancer subjects. These observations demonstrate that methylation patterns in primary cancers of the aerodigestive tract are site-specific. Such differences challenge the prevailing concepts of the pattern of global methylation on carcinogenesis. Likely reasons for these observations have been discussed elsewhere (Piyathilake CJ, Bell WC, Jones J, Henal OL, Heimburger DC, Niveleau A, Grizzle G. The patterns of global DNA methylation in oral carcinogenesis, accepted for publication).

The differences in global DNA and histone methylation between neoplastic/dysplastic and normal tissues may be secondary in nature reflecting neoplatic progression and may be unrelated to the process of carcinogenesis, but it is interesting that the two events follow a similar pattern in these tissues. Although the mechanisms of the pattern of DNA and histone methylation and their association to each other in oral carcinogen- 
Table 2

Correlations between 5-mc (DNA methylation) and H3-lys 4 and H3-lys 9 (histone methylation), and between H3-lys 4 and H3-lys 9 in different tissues. Spearman correlation coefficients (r) and p values are shown

$\begin{array}{lcccc} & \begin{array}{c}\text { Normal oral } \\ \text { epithelium of non-cancer }\end{array} & \begin{array}{c}\text { Uninvolved oral } \\ \text { epithelium of cancer }\end{array} & \begin{array}{c}\text { Dysplasia } \\ \text { of cancer }\end{array} & \text { Cancer } \\ \text { 5-mc and H3-lys 4 } & r=0.63, p<0.0001 & r=0.43, p=0.008 & r=0.49, p=0.001 & r=0.59, p=0.0003 \\ \text { 5-mc and H3-lys 9 } & r=0.62, p<0.0001 & r=0.47, p=0.003 & r=0.38, p=0.040 & r=0.48, p=0.004 \\ \text { H3-lys 4 and H3-lys 9 } & r=0.77, p<0.0001 & r=0.55, p=0.0005 & r=0.49, p=0.001 & r=0.54, p=0.002\end{array}$

esis are unclear, the consistency in results across several lesions of the oral epithelium indicate that these two methylation events are likely to be associated with each other. Further studies are needed to evaluate their significance in the process of carcinogenesis.

\section{References}

[1] A.P. Feinberg and B. Vogelstein, Hypomethylation distinguishes genes of some human cancers from their normal counterparts, Nature 301 (1983), 89-92.

[2] C.J. Piyathilake, A. Niveleau and W.E. Grizzle, Role of global DNA methylation in lung carcinoma, in: Immunohistochemistry of in situ Hybridization of Human Carcinomas, (Vol. 1), Molecular Genetics, Lung and Breast Carcinomas, Graphic World Publishing Service.

[3] C.J. Piyathilake, A.R. Frost, W.C. Bell, D. Oelschlager, H. Weiss, G.L. Johanning, A. Niveleau, D.C. Heimburger and W.E. Grizzle, Altered global methylation of DNA: an epigenetic difference in susceptibility for lung cancer is associated with its progression, Hum. Pathol. 32 (2001), 856-862.

[4] C.J. Piyathilake, G.L. Johanning, A.R. Frost, M.A. Whiteside, U. Manne, W.E. Grizzle, D.C. Heimburger and A. Niveleau, Immunohistochemical evaluation of global DNA methylation: comparison with in vitro radiolabeled methyl incorporation assay, Biotechnic. Histochem. 75 (2000), 251-258.

[5] E.E. Cameron, K.E. Bachman, S. Myohanen, J.G. Herman and S.B. Baylin, Synergy of demethylation and histone deacetylase inhibition in the re-expression of genes silenced in cancer, Nat. Genet. 21 (1999), 103-107.

[6] H. Tamaru and E.U. Selker, A histone $\mathrm{H}_{3}$ methyltransferase controls DNA methylation in Neurospora crassa, Nature $\mathbf{4 1 4}$ (2001), 277-283.

[7] J.A. Fahrner, S. Eguchi, J.G. Herman and S.B. Baylin, Dependence of histone modifications and gene expression on DNA hypermethylation in cancer, Cancer Res 62 (2002), 72137218.

[8] J.C. Rice and C.D. Allis, Histone methylation versus histone acetylation: new insights into epigenetic regulation, Curr.
Opinion Cell Biology 13 (2001), 263-273.

[9] J.G. Herman and S.B. Baylin, Promoter-region hypermethylation and gene silencing in human cancer, Curr. Topics $\mathrm{Mi}$ crobiol. Immunol. 249 (2000), 35-54.

[10] J. Lewis and A. Bird, DNA methylation and chromatin structure, FEBS Lett 285 (1991), 155-159.

[11] K. Higashimoto, T. Urano, K. Sugiura, H.Yatsuki, K. Joh, W. Zhao, M. Iwakawa, H. Ohashi, M. Oshimura, N. Niikawa, T. Mukai and H. Soejima, Loss of CpG methylation is strongly correlated with loss of histone $\mathrm{H}_{3}$ lysine 9 methylation at DMR-LIT1 in patients with Beckwith-Wiedemann syndrome, Am. J. Hum. Genet. 73 (2003), 948-956.

[12] P.L. Jones, G.J. Veenstra, P.A. Wade, D. Vermaak, S.U. Kass, N. Landsberger, J. Strouboulis and A.P. Wolffe, Methylated DNA and MeCP2 recruit histone deacetylase to repress transcription, Nat. Genet. 19 (1998), 187-191.

[13] P.W. Laird and R. Jaenisch, The role of DNA methylation in cancer genetic and epigenetics, Annu. Rev. Genet. 30 (1996), $441-464$.

[14] S.B. Baylin and J.G. Herman, DNA hypermethylation in tumorigenesis: epigenetics joins genetics, Trends Genet 16 (2000), 168-174.

[15] S.B. Baylin, J.G. Herman, J.R. Graff, P.M. Vertino and J.P. Issa, Alterations in DNA methylation: a fundamental aspect of neoplasia, Adv. Cancer Res. 72 (1998), 141-196.

[16] S. Rea, F. Eisenhaber, D. O'Carroll, B.D. Strahl, Z.W. Sun, M. Schmid, S. Opravil, K. Mechtler, C.P. Ponting, C.D. Allis and T. Jenuwein, Regulation of chromatin structure by sirespecific histone $\mathrm{H}_{3}$ methyltransferases, Nature 406 (2000), 593-599.

[17] W.E. Grizzle, R.B. Myers, U. Manne and S. Srivastava, Immunohistochemical evaluation of biomarkers in prostate and colorectal neoplasia, in: John Walker's Methods in Molecular Medicine - Tumor Marker Protocols, M. Hanausek and Z. Walaszek, eds, Humana Press, New Jersey, 1998, pp. 143-160.

[18] X. Nan, H.H. Ng, C.A. Johnson, C.D. Laherty, B.M. Turner, R.N. Eisenman and A. Bird, Transcriptional repression by the methyl-CpG-binding protein $\mathrm{MeCP} 2$ involves a histone deacetylase complex, Nature 393 (1998), 386-389.

[19] Y. Kondo, L. Shen and J.P. Issa, Critical role of histone methylation in tumor suppressor gene silencing in colorectal cancer, Mol. Cell Biol. 23 (2003), 206-215. 


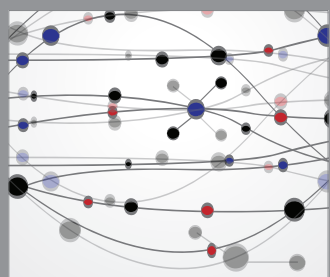

The Scientific World Journal
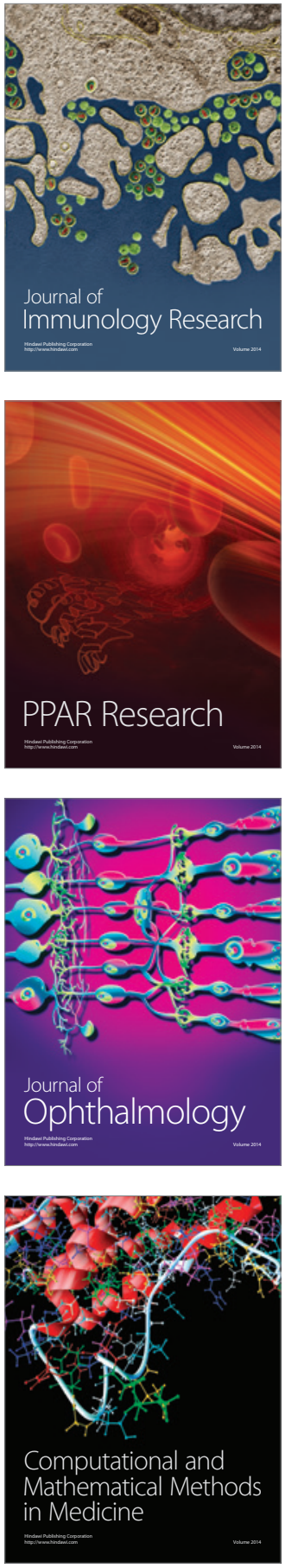

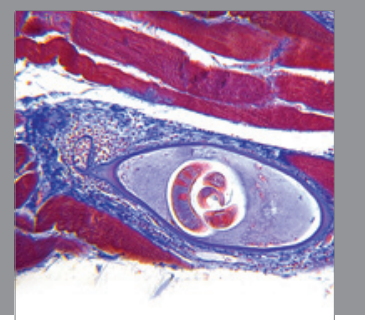

Gastroenterology

Research and Practice
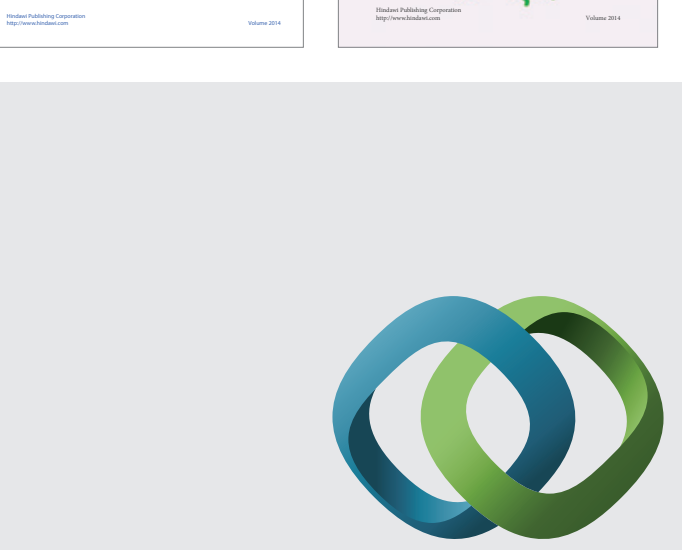

\section{Hindawi}

Submit your manuscripts at

http://www.hindawi.com
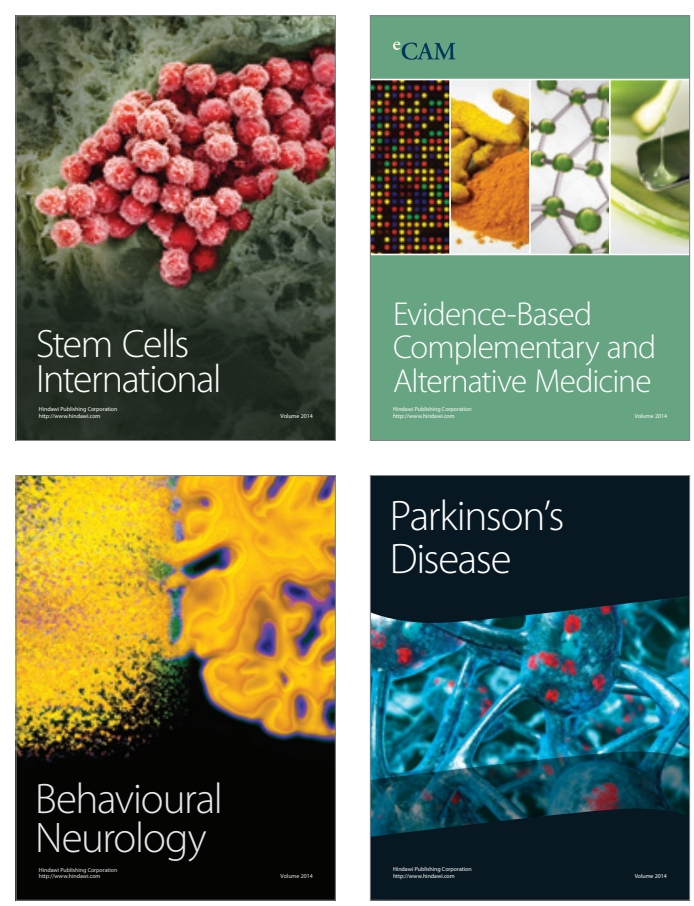

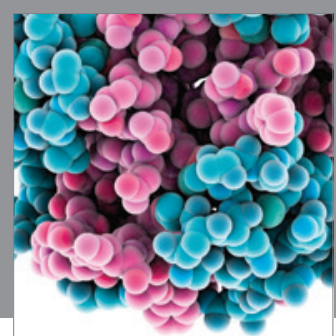

Journal of
Diabetes Research

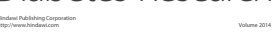

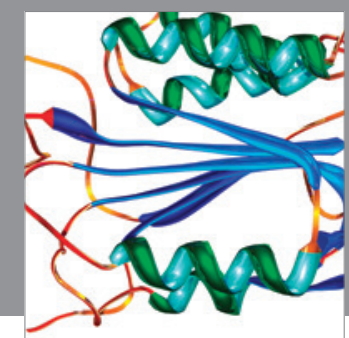

Disease Markers
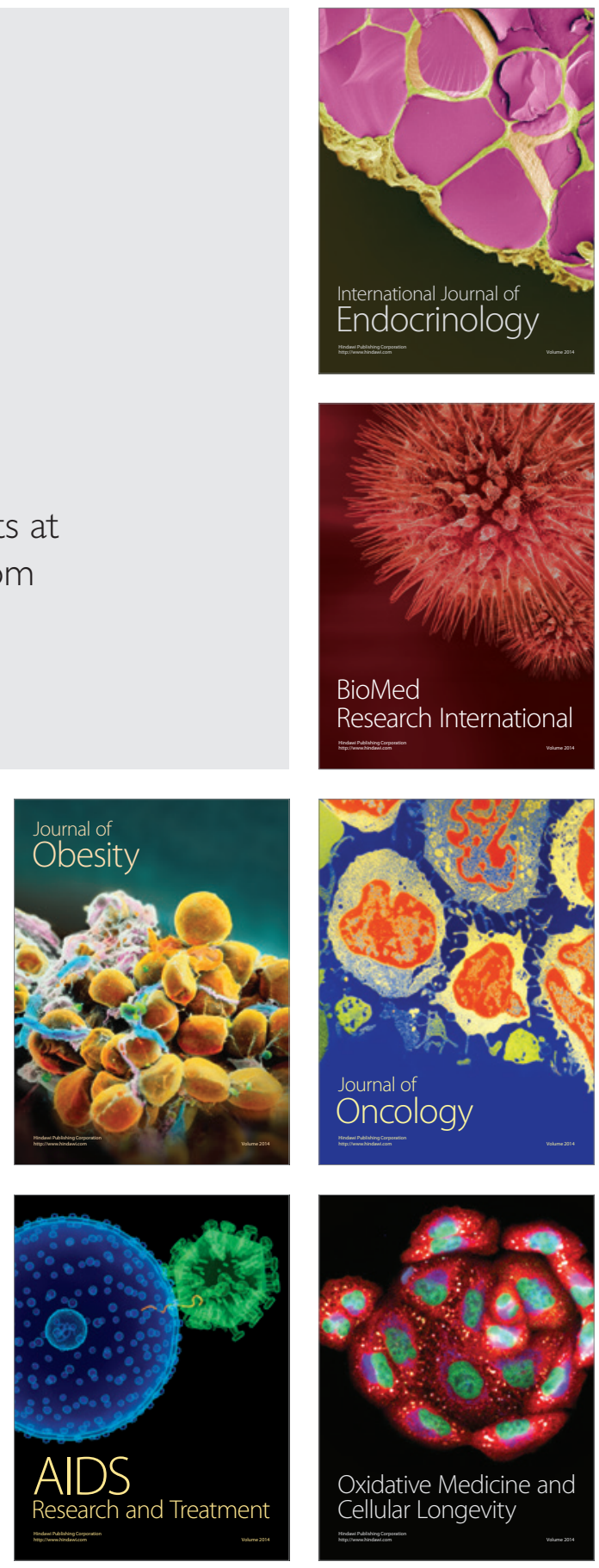